\section{RGS, Shell and Nigeria}

SIR - The headline to your News story about relations between the Royal Geographical Society (with the Institute of British Geographers) and Shell - "UK geographers vote to cut links with Shell (Nature 379, 104; 1996) - gives a wrong impression. Some geographers voted thus, but by no means all.

We have more than 13,000 fellows and members. Of these, 900 were at our academic annual conference in Glasgow, of whom fewer than 200 attended the open meeting that discussed Shell's corporate patronage of the society. In fact, 156 fellows supported the motion to sever links with Shell. That is only 1.1 per cent of our fellowship.

I will not comment on Shell's environmental and political record in Nigeria until after we have learned more from the forum planned here later this year. I would imagine, however, that Shell would welcome a return to democratic rule in that unfortunate country as much as we all would.

I can add to what you say about Shell's record as a benefactor of research. The company has been a generous supporter of our work for many years. It sponsors a department that gives training and advice to people going on expeditions; it subsidized a prize-winning schools teaching pack on rainforests; it paid for a purpose-built rainforest research station in Borneo; and it has often helped our scientists in the field.

This patronage has been entirely disinterested. Shell has asked for nothing in return. It was our idea to call the company Corporate Patrons, alongside three other British companies. Shell scarcely mentions this support: it appears only on page 14 of its leaflet Shell in Society among hundreds of other good causes the company helps.

\section{John Hemming}

Royal Geographical Society,

1 Kensington Gore,

London SW7 2AR, UK

\section{Not so black}

SIR - In the leading article "Europe's black sheep", you write: "Greece (where Aristotle used to live) is at the bottom of all lists; total spending on research and development runs at about 0.5 per cent of gross domestic product" (Nature 378, 222; 1995). In this context, the parenthetic phrase is polemic, ironic and - to use your own words - "to some degree unfair". Furthermore, this phrase does not place Greece deeper in "all lists". So there is no additional message. More importantly, however, this statement creates doubts about your journalistic objectivity. Scientists who live and work in Greece and who publish their research results in international peer-reviewed journals (including Nature) will not be amused.

Research done in Greece compares well with that in Italy and other larger member countries of the European Union (EU). And in order to put Professor Antonio Ruberti's proposal in its proper context, it would have also have helped if, as well as publishing the percentages of gross domestic product spent on research and development in EU member countries, you had shown other related indices. For instance, Greece has the highest military spending per capita of all NATO countries, mainly because of its strategic position and the requirements of the recently ended Cold War. Greece has had to buy military equipment from Britain and France, among others, and support in this way the military research in those countries, on which as you indicate, these two countries "spend substantial sums...".

Athanassios Giannis

Institute for Organic

Chemistry and Biochemistry,

University of Bonn,

Gerhard-Domagk-Strasse 1,

D-53121 Bonn, Germany

\section{Clinical trials}

SIR - Recent correspondence on xenotransplantation (Nature 378, 434; 1995) has demonstrated the need, in the words of David White, for "plans for a clinical programme dealing with such issues as disease control, ethical considerations and regulatory affairs [to] be initiated as soon as possible".

Such plans have in fact been initiated. In the United Kingdom, the Nuffield Council on Bioethics will publish on 6 March a report on xenotransplantation that has been in preparation since early 1995. The Department of Health has established a committee under Professor Ian Kennedy to address the issues; a report is expected in mid-1996. In the United States, the Institute of Medicine is producing a report on xenotransplantation and guidelines on disease control are shortly due from the Public Health Service.

It is to be hoped that "the final decision on when to commence clinical trials will be based" not only on "the experimental data" but also on public discussion and on the development of a regulatory framework that is rapidly being put in place.

\section{David Shapiro}

Nuffield Council on Bioethics,

Nuffield Foundation,

28 Bedford Square,

London WC1B 3EG, UK

\section{No way back?}

SIR - We endorse Pere Puigdomènech's opinion (Nature 378, 126; 1995) that Spanish science is on the brink of a crisis. Until a few years ago, postdocs returning from a period abroad could easily find a position within the research establishment, either at a university or at the Spanish Council for Scientific Research (CSIC). That seems no longer to be the case, at least for most young scientists. The situation is especially worrying in the universities, which account for almost 80 per cent of Spanish research. The strenuous efforts in many Spanish universities in the past few years to improve the quality of science and the training of new scientists are now in jeopardy.

Although the Socialists increased research funding during their early years in government, they were at the same time sowing the seeds of the present problems. The Socialist government started to clog up the university system early in 1984 when it convened a one-off extraordinary board of evaluation (called Idoneidad, Spanish for 'suitability') to make appointments to faculty positions. In many cases, people who could barely fulfil the legal requirements (little more than a PhD and some teaching experience) became university professors, regardless of their scientific ability.

And during the budgetary expansion of the mid-1980s, positions were also being filled by the regular Spanish system of evaluation known as Oposiciones, which does take into account the scientific productivity of the candidate. And in Spain, a professorship is a permanent position with the status of a civil servant appointed for life.

Many university departments are now staffed by people with an average age of 40 to 45 . With the compulsory retirement age for academic staff recently raised to 70 , few positions will become available in the next 25 or 30 years. Moreover, there are no nontenured professors or researchers working under contract in universities. For postdocs on a three-year contract paid by the government after their return from abroad, there is no opportunity for the renewal of their contracts anywhere in Spain. So very few of the postdocs now returning will ever have access to a faculty position within a university department. To make things even worse, universities are producing an increasing number of PhDs just to keep up their funding levels and scientific productivity.

As two postdocs with their three-year appointments about to expire we wonder if emigration is once again the only future for Spanish scientists.

Yolanda S. Lopez-Boado

Fernando Segade

Departamento de Bioquimica

y Biologia Molecular,

Universidad de Oviedo,

33006 Oviedo,Spain 